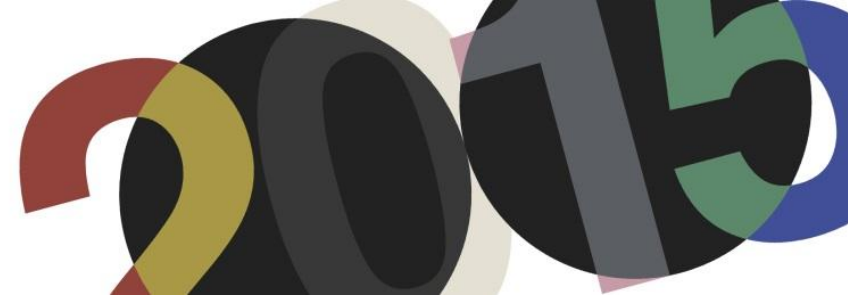

DOI: http://dx.doi.org/10.4995/LC2015.2015.910

\title{
La Villa Sarabhai. La riqueza de lo ambiguo
}

\author{
A. García González, V. Mas Llorens, J. Santatecla Fayos \\ Escuela Superior de Arquitectura de Valencia
}

\begin{abstract}
Resumen: La Villa Sarabhai ha sido considerada en gran parte de las referencias críticas como un paradigma de la "architecture femelle" por absorber el emplazamiento y por sus espacios abovedados, llegando a ser asociada con la arquitectura rústica, folklórica, incluso primitiva. Sin embargo, la evolución del proyecto muestra que no existe ninguna voluntad por parte de Le Corbusier de integrar la villa en su entorno ni de rendir tributo a la arquitectura tradicional. Le Corbusier continúa evolucionando dando un nuevo giro a estrategias arquitectónicas ya consolidadas y resistiéndose a las clasificaciones: genera una planta libre mediante muros; transforma la terraza jardín de una habitación sin techo en una pradera; y en lugar de laminar el espacio en vertical lo lamina en horizontal. No obstante, el objetivo de su arquitectura se mantiene firme desde los años 20, generar una sensación continua de desconcierto. En la Villa Sarabhai el visitante no es capaz de afirmar si se encuentra en un edificio anclado al terreno o que se posa sobre él, en una construcción arquitrabada o abovedada, arriba o abajo, dentro o fuera, ni siquiera si lo que percibe es real o una representación de la realidad. Así, la ambigüedad se convierte en el medio para alcanzar la riqueza arquitectónica.
\end{abstract}

Abstract: Villa Sarabhai is considered by many critics to be a paradigm of "architecture femelle", because it absorbs the setting and has vaulted spaces, which are elements associated with a rustic, folkloric, and even primitive, architecture. However, the evolution of the project shows that Le Corbusier did not intend to integrate the villa into the landscape or pay tribute to traditional architecture. Le Corbusier kept evolving. He added new twists to his consolidated architectonic strategies and defied classification: he generated a free plan by using walls; he transformed the garden terrace from a room without a ceiling into a prairie; and, instead of laminating the space in vertical, he laminated it in horizontal. Nevertheless, the aim of his architecture remained constant since the 1920s, generating a permanent feeling of bewilderment. Inside Villa Sarabhai, visitors are not able to confirm if they are in a building which is anchored to the ground, or in one which is resting on it; in an orthogonal construction or in a vaulted one; up or down; inside or outside; not even sure whether what they perceive is real or a representation of reality. The ambiguity becomes the means for reaching the architectonic richness.

Palabras clave: Le Corbusier; Villa Sarabhai; Ahmedabad; Architecture femelle; Bóveda; Ambigüedad. Keywords: Le Corbusier; Villa Sarabhai; Ahmedabad; Architecture femelle; Vault; Ambiguity.

\section{Un paradigma en la arquitectura de Le Corbusier.}

La importancia atribuida por Le Corbusier a la Villa Sarabhai queda patente en el número de páginas que le dedica en la Euvre Complète 1952-1957, muy superior al de sus coetáneas Villa Shodhan y Maisons Jaoul. Sin embargo, mientras estas últimas despertaron el interés de la crítica incluso antes de su finalización, la Villa Sarabhai fue ignorada hasta finales de los años 60, cuando Von Moos se refiere brevemente a ella en su monografía sobre Le Corbusier, dentro de un capítulo titulado La cubierta ondulada ${ }^{1}$. Von Moos sostiene que la Villa Sarabhai es la culminación de una de las dos corrientes antitéticas que recorren la obra del arquitecto, la architecture femelle, que comienza con las casas Monol (1919), por oposición a la architecture mâle, iniciada con las casas Citrohan (1922) y finalizada en la Villa Shodhan (1951). Compara estas casas con grutas cuyas formas rupestres introducen un vocabulario folklórico que recuerda a la arquitectura antigua de las islas griegas.

\footnotetext{
${ }^{1}$ Von Moos, Stanislaus: Le Corbusier. Barcelona: Editorial Lumen, 1977.pp. 160-165.
} 
La idea de dos genealogías en la obra de Le Corbusier había sido establecida en 1965 por Serenyi en su artículo Le Corbusier`s Changing Attitude Toward Form ${ }^{2}$, aunque éste no menciona la Villa Sarabhai, considerando el último ejemplar de esta línea de investigación a las Villas Jaoul (1951). Serenyi sostiene que el tipo Citrohan se caracteriza por ser angular y dominar el emplazamiento, mientras que el tipo Monol es ondulante y absorbe el emplazamiento. Desde entonces hasta la actualidad otros autores entre los que destacan Curtis ${ }^{3}$ o Jencks ${ }^{4}$ han insistido en la existencia de dos tradiciones en la arquitectura doméstica de Le Corbusier y en la adscripción de la Villa Sarabhai a la architecture femelle, que relacionan con un tipo de implantación, un tipo de cubierta y un tipo de construcción que constituye una vuelta a lo primitivo. Sin embargo, la exclusión de la Villa Sarabhai como ejemplo final de la genealogía Monol por parte de Serenyi, resulta sorprendente dada la repercusión de su escrito. Ésta queda explicada en un artículo posterior Timeless but of its Time: Le Corbusier`s Architecture in

India $^{5}$. En él se hace referencia al exterior angular de la villa, obviado en otras críticas, afirmando que la villa es la yuxtaposición de los dos tipos, el masculino y el femenino, aunque reconoce que el interior constituye la raison d'être de la casa. El comentario de Serenyi plantea ciertas dudas sobre la aptitud de la Villa Sarabhai como integrante de la architecture femelle. Además, la mayor parte de las escasas referencias entorno a la villa se centran en su versión construida y constituyen líneas anecdóticas dentro de textos que tratan aspectos más amplios de la obra de Le Corbusier. Así pues, se detecta un vacío crítico relativo al análisis de la evolución de la obra que demuestre la hipótesis establecida. Esta investigación no tiene como objetivo realizar una descripción, siguiendo una línea temporal, de los documentos del proyecto que se conservan en la Fondation Le Corbusier, trabajo realizado exhaustivamente por Suarez ${ }^{6}$. Sino un análisis a lo largo del tiempo de aquellos pasos importantes, relativos tanto a la implantación, como a la forma y espacio generados por el diseño de la cubierta y el sistema constructivo, que permita arrojar luz sobre la idoneidad de la Villa Sarabhai como paradigma de la architecture femelle.

\section{El desarrollo de una idea.}

La Villa Sarabhai debía construirse en el interior de una finca de exuberante naturaleza llamada The Retreat, situada en una zona de Ahmedabad conocida como Shahibagh, al Norte del corazón de la ciudad y próxima a la rivera Este del río Sabarmati. El terreno era propiedad del suegro de Manorama Sarabhai, Seth Ambalal Sarabhai ${ }^{7}$, quien había construido una gran casa colonial para su familia. Con el paso de los años el patriarca había ido favoreciendo la emancipación de sus hijos cediéndole a cada uno de ellos una parte de la finca en la que construirse su propia vivienda. Cuando Manorama Sarabhai enviudó no se hizo excepción y le fue ofrecido un terreno en el que vivir con sus dos hijos, Suhrid y Anand, de diez y trece años respectivamente.

\footnotetext{
${ }^{2}$ Serenyi, Peter: "Le Corbusier`s Changing Attitude Toward Form". En Journal of the Society of Architectural Historians. Marzo 1965, vol XXIV, №2. pp. 15-19.

${ }^{3}$ Curtis, William: Le Corbusier. Ideas and Forms. London: Phaidon Press Limited, 2003. pp. 210-212.

${ }^{4}$ Jencks, Charles: Le Corbusier and the Continual Revolution in Acrchitecture. New York: The Monacelly Press, Inc. and Charles Jencks, 2000. pp. 307-308.

${ }^{5}$ Serenyi, Peter: "Timeless but of its Time: Le Corbusier`s Architecture in India". En Brooks, H.Allen: Le Corbusier. New Jersey: Princeton University Press, 1987. pp. 172-175.

${ }^{6}$ Suárez, Maria Candela: "Villa de Mrs Manorama Sarabhai". En Le Corbusier plans. CD10. París: Echelle-1 - Fondation Le Corbusier, 2005-2010.

${ }^{7}$ Seth Ambalal Sarabhai, era uno de los hombres más influyentes de la ciudad. Había consolidado la gran empresa algodonera de su familia, además de haber sido presidente de la Asociación de Hilanderos y miembro del equipo municipal de Ahmedabad.
} 


\subsection{Dos casas en una. La dualidad Nave-Ala.}

El 26 de noviembre de 1951 el encargo ya había sido formalizado a través de una nota ${ }^{8}$ en la que se detallaban las necesidades funcionales de la villa. El programa debía estar fraccionado en dos edificios, uno ocupado por la villa principal y el otro reservado al servicio. El edificio principal debía estar dividido a su vez en dos zonas, una destinada a la Sra Sarabhai y su hijo menor y la otra dedicada exclusivamente al primogénito. La primera debía constar de: un garaje abierto y cubierto para un solo coche, un salón con un comedor separable, una bibliotecaestudio para la Sra Sarabhai, un baño completo, una cocina independiente con una gran despensa con reservas para seis meses, una pequeña habitación para el servicio, un dormitorio con baño para la Sra Sarabhai y otro para su hijo menor, ambos con terrazas al aire libre y verandas ${ }^{9}$ con camas para dormir al exterior. La segunda debía incluir un dormitorio con baño y un estudio con cocina o kitchenette. Finalmente, la nota hace referencia a la construcción de una piscina que debía estar en contacto con la casa. Junto a las especificaciones de carácter funcional, se incluyen una serie de condicionantes relacionados con la implantación. En primer lugar, el terreno estaba 4 pies por debajo del nivel del agua y la rivera del río Sabarmati podía desbordarse con los monzones, en consecuencia resultaba necesario elevar la casa. En segundo lugar, la casa debía orientarse para captar los vientos frescos del Sud-Oeste y evitar los vientos fríos del Norte en invierno. El escrito añade además, que la ley no permitía construir a menos de 15 pies del linde de la propiedad.

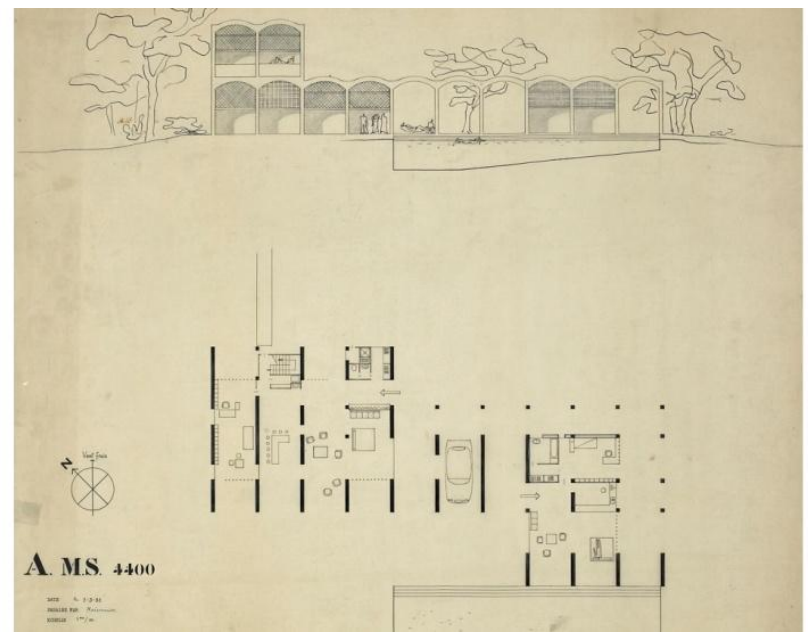

1. Planta baja y alzado Sud-Oeste de la primera entrega de la Villa Sarabhai. Marzo 1952, FLC 6675.

Los primeros documentos fechados que se conservan de la Villa Sarabhai datan del 7 de marzo de 1952 y constituyen la primera entrega de planos preparada por el atelier para el tercer viaje de Le Corbusier a la India. La entrega consta de dos documentos: el documento FLC 6675, que contiene el alzado Sud-Oeste y la planta baja; y el documento FLC 6677, con la implantación y la planta primera. En 1953, Le Corbusier publica parte de estos planos en la CEuvre Complète 1946-1952, revelando el objetivo principal de su propuesta:

"Le plan cherche à réaliser les meilleures conditions d'ombre et de ventilation naturelle" 10

\footnotetext{
${ }^{8}$ Nota conservada en la Fondation Le Corbusier detallando el programa de la Villa Sarabhai FLC P3-7-20.

${ }^{9}$ La palabra veranda proviene del término inglés verandah, que a su vez procede del término hindi varandā, empleado en la India para denominar a espacios exteriores cubiertos, asociados a un edificio o a un jardín, que proporcionan cobijo del sol y de la lluvia.

${ }^{10}$ Boesiger, Willy: Le Corbusier. Cuvre complète 1946-1952. $8^{\text {a }}$ ed. Zurich: Les Editions d’Architecture, 1985. p. 160.
} 
En el plano de implantación, se aprecia que la forma irregular de la parcela, la posición Nord-Este del viario principal y la presencia de tres pequeñas construcciones, cuya integridad debía ser preservada, obligan a Le Corbusier a disponer la edificación en la zona Este de la propiedad, próxima a los lindes sin viario. La edificación se sitúa sobre un montículo artificial, señalado en los planos mediante una línea orgánica, con el fin de responder a posibles desbordamientos del río, y se orienta en la dirección Sud-Oeste siguiendo las indicaciones de la nota de noviembre.

El único alzado que se dibuja en esta propuesta, y por tanto el que se erige en principal, es el Sud-Oeste, con vistas al jardín. El edificio se percibe como una adición de módulos tridimensionales, en los que la geometría dominante es la curva, que generan un volumen complejo, evitando la monotonía gracias a la división asimétrica del programa. De este modo, la villa presenta una dualidad entre dos sistemas de generación: la adición de unidades abovedadas y la división del programa en dos alas, tal y como exigía la Sra Sarabhai.

La independencia tanto formal como espacial de cada una de las naves se alcanza mediante dos mecanismos. Desde el exterior, la sombra generada por las verandas, situadas en sendas fachadas principales, pone de manifiesto el carácter elemental de cada una de las naves. En el interior, su cubierta imprime al espacio una marcada direccionalidad. Cabe resaltar que las bóvedas son sustentadas por un sistema mixto de muros y pilares, cuando la estructura podría haber sido íntegramente resuelta mediante un sistema puntual. Sin embargo, los pilares tan sólo se emplean para aumentar la dimensión de ciertos espacios y abrir la casa hacia el Sud-Este. Así pues, la planta presenta una gran rigidez, ya que cada unidad funcional queda restringida a una unidad espacial incluso en aquellos espacios que aúnan varias naves, que quedan divididos en varios ambientes, lo que indica que la introducción de muros en el sistema no es una decisión puramente estructural.

La diferenciación de las dos alas dentro del sistema modular se produce mediante tres estrategias. En primer lugar, de las 10 unidades abovedadas que forman la villa en planta baja, las cuatro situadas al Nord-Oeste sobresalen respecto al plano de la fachada de acceso, mientras las tres situadas al Sud-Este lo hacen respecto a la fachada opuesta, dando lugar a una tensión asimétrica en planta entre ambas. En segundo lugar, las tres bóvedas que quedan entre sendas alas no son ocupadas por espacios interiores, de modo que la oposición lleno-vacío las articula en planta al tiempo que permite su diferenciación en alzado. Por último, el ala Nord-Oeste consta de dos bóvedas en planta primera, mientras que la opuesta tan sólo se desarrolla en planta baja, lo que atiende no sólo a una división funcional, sino también a una significación del ala más representativa. Así, el ala Nord-Oeste contiene en planta baja los espacios públicos de la vivienda y en la planta primera los dormitorios de la Sra Sarabhai y de su hijo menor, mientras el ala Sud-Este queda reservada al primogénito. El espacio de articulación entre ambas alas no se concibe como un espacio de encuentro o como un distribuidor, sino como un filtro o una exclusa que asegura la independencia de cada una de las alas dentro de la superestructura general. El ejemplo más ilustrativo de ello es que la nave central de la articulación es destinada al cobijo del automóvil. Así pues, la villa se concibe como dos casas en una.

\subsection{Unidad espacial versus unidad funcional.}

La discusión de la documentación entregada con la Sra Sarabhai tiene como resultado una serie de comentarios escritos sobre sendas copias de los planos originales, FLC 6676 y 6678. En primer lugar, se debe tratar de invertir la posición de las dos alas de la casa para que el bloque de servicio quede al Este, más próximo a la carretera $^{11}$. En segundo lugar, un sombreado rosa diferenciando el espacio interior del exterior, deja constancia

\footnotetext{
11 "essayer de reverser le plan/ de A en b de façon/ à avoir les domestiques/ à l'est vers la route". FLC 6678.
} 
de la necesidad de solventar la ambigüedad de los planos originales. En tercer lugar, se indica la necesidad de incrementar el salón en una nave, absorbiendo el comedor y sustituyendo el muro que los separa por pilares. A pesar del temprano estadio en el que se encuentra el proyecto, algunos de los croquis y comentarios que les acompañan adelantan cuestiones constructivas. En el documento FLC 6676, junto a los muros se hace referencia a una construcción con ladrillos vistos, enlucidos y coloreados en algunos puntos, así como a la construcción de muros en piedra. En este mismo documento, varios de los croquis exploran el sistema de construcción de las bóvedas. En uno de ellos se explica la formación de la bóveda disponiendo primero una hilada de azulejos de 7"x7" a modo de cimbra sobre la que colocar una hilada de ladrillo; mientras que en otro se aprecia como las bóvedas descansan sobre vigas de canto que a su vez apoyan sobre los muros, lo que permite sustituir los muros por pilares siempre que sea necesario. Un símbolo de interrogación acompaña a los dibujos indicando lagunas en el sistema.

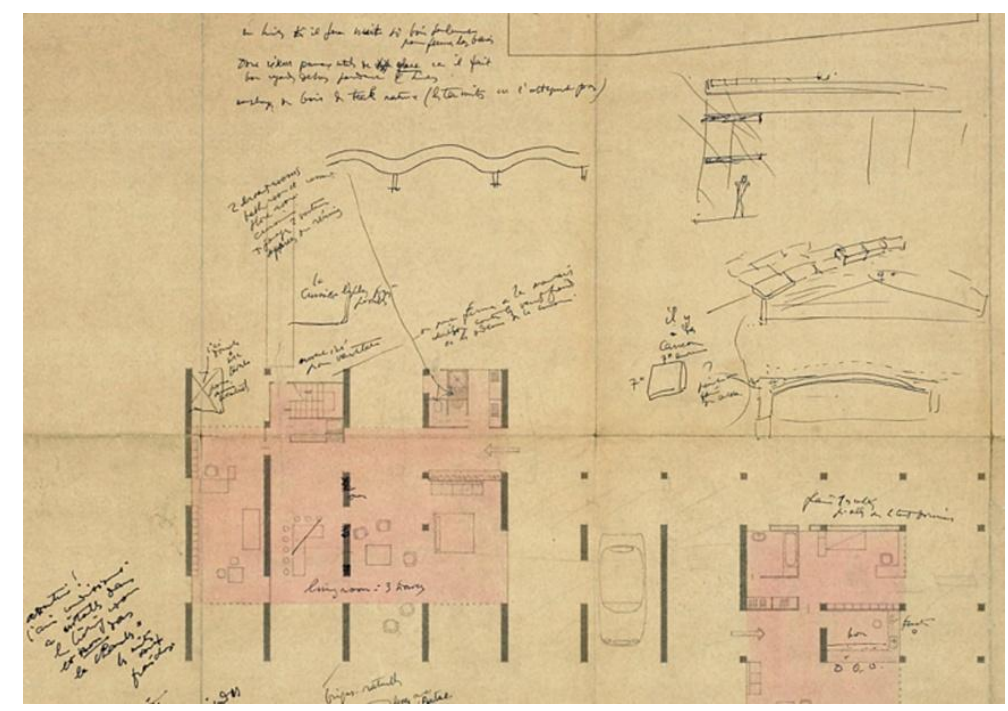

2. Correcciones sobre el proyecto de marzo de 1952 de la Villa Sarabhai. Detalle del documento FLC 6676.

El documento FLC 6772 contiene dos bocetos de implantación que tratan de responder a las peticiones realizadas por Mrs Sarabhai. En el primero de ellos, se trata de acercar el bloque de servicio a la carretera sin tener que intercambiar las posiciones de las dos alas, orientando el eje longitudinal del edificio en la dirección Norte-Sur y situando el edificio de servicio al Norte, alineado con él. En el segundo, la nueva orientación se mantiene, pero además se invierte la posición de las dos alas. La piscina, rectangular en la primera entrega, adquiere un contorno dual, combinando ángulos rectos en las zonas próximas al edificio con curvas en las zonas más próximas al jardín, convirtiéndose en un elemento de transición entre lo artificial y lo natural. 


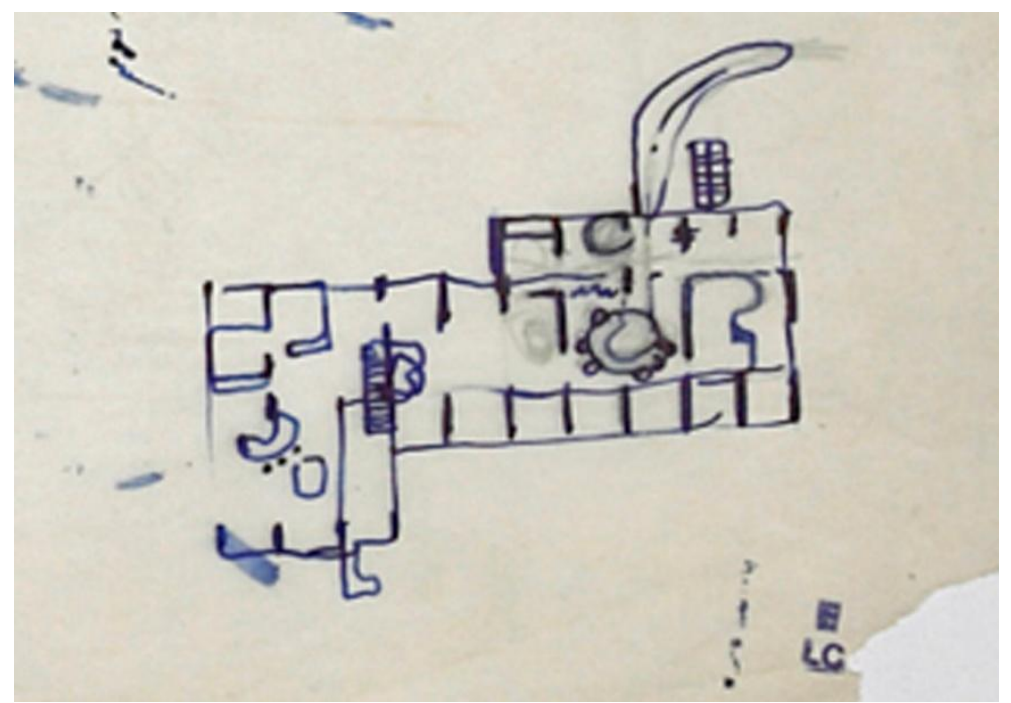

3. Boceto de la planta baja de la Villa Sarabhai. Detalle del documento FLC 31904.

El documento FLC 31904, desarrolla el esquema de la planta baja correspondiente al segundo boceto del documento FLC 6772, aunque el edificio vuelve a su orientación original, es decir, con su fachada principal orientada al Sud-Oeste y no al Oeste. En el interior, tal y como se anunciaba en el documento FLC 6676, salón y comedor pasan a formar un único espacio, aunque se divide en tres ambientes correspondientes a cada una de las tres naves que lo constituyen, manteniendo la rigidez de la propuesta anterior. Sin embargo, en un pequeño boceto situado en el ángulo inferior del documento, el comedor deja de estar adscrito a una única bóveda, ocupando el espacio intermedio entre dos de ellas. Los pilares son sustituidos íntegramente por muros de diferentes longitudes entre los cuales se infiltran formas orgánicas, de modo que el sistema lineal comienza a imponerse al puntual, pero adquiriendo su flexibilidad.

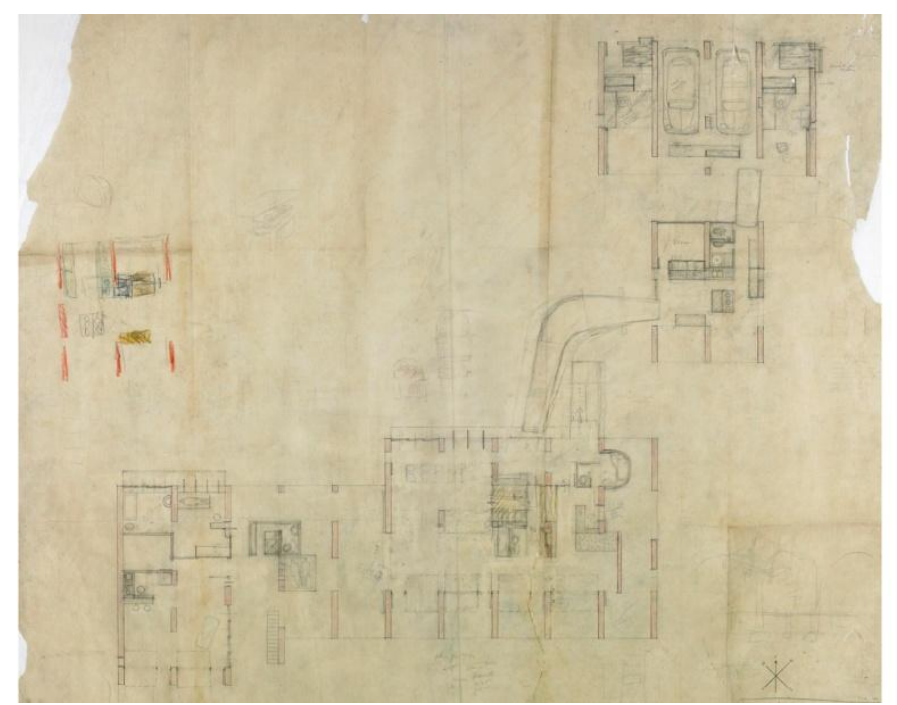

4. Boceto de la planta baja de la Villa Sarabhai de mayo 1952. FLC 31882.

El 21 de mayo de 1952 se continúa el desarrollo del esquema de planta baja en el documento FLC 31882. El volumen principal mantiene las premisas de fluidez espacial e inserción de formas orgánicas del pequeño boceto del documento FLC 31904, pero con mayor mesura. A pesar de que los muros no son continuos, sus alineaciones siguen presentes, incluso en los espacios más diáfanos como el salón-comedor y el acceso. Si en la propuesta de marzo cada unidad funcional quedaba limitada por una unidad espacial; en esta propuesta diversas unidades 
funcionales se disponen a caballo entre dos naves contiguas. Ejemplo de ello son el baño situado entre la veranda del ala del primogénito y la primera nave de la articulación, o el baño y la habitación ubicados entre las dos últimas naves al Sud-Este del ala principal. En el segundo ejemplo expuesto, se observa cómo Le Corbusier encuentra en esta oposición unidad espacial-unidad funcional el acomodo para las formas orgánicas dibujadas en el boceto FLC 31904.

\section{3 ¿Excavado o Construido?}

Los documentos FLC 6768A, B, C y D contienen cuatro perspectivas, que aunque no están datadas, tanto por la forma del edificio principal como por la de la piscina, cabe pensar que fueron desarrolladas entre mayo y junio de 1952. En ellas se estudia tanto el diseño de la cubierta como la relación del edificio con el terreno. Las propuestas A y D se presentan como extremos opuestos dentro del proceso de ideación de la cubierta. En el documento A, el alzado del proyecto de marzo (FLC 6675), sufre una transformación del contorno superior de la cubierta, de modo que éste ya no corresponde con los trasdoses de la bóvedas, sino con una curva que las va uniendo de dos en dos de manera similar a las casas Jaoul, a pesar de que las bóvedas impares mantienen su trasdós intacto. La agrupación de pares de bóvedas, aunque aporta variedad a la unidad, provoca un aumento del canto de la cubierta incrementando la sensación de pesadez, efecto que queda reforzado por el sólido anclaje del edificio al terreno. En la propuesta D, las bóvedas recuperan la uniformidad de la propuesta de marzo y reducen su grosor a la mínima expresión. La palabra Shell (cáscara), manuscrita sobre el dibujo ilustra con claridad la pretensión de Le Corbusier de construir una cubierta lo más ligera posible. La ingravidez de la cubierta obliga a disponer vigas transversales sobre las bóvedas para arriostrarlas, por lo que resulta necesario prolongar los muros que conforman los testeros para ocultar su canto. Las opciones B y C son similares a la perspectiva D pero sin las vigas de arriostramiento. En ellas el montículo que elevaba la villa para evitar inundaciones desaparece, de modo que el forjado de planta baja queda elevado respecto al nivel natural del suelo, apoyado en los muros de carga, debilitando la relación entre construcción y terreno. En los cuatro documentos se observa una distinción material entre los elementos de carga y soporte. Así las bóvedas se representan en un material continuo, mientras que los muros son de ladrillo. El documento FLC 31894, que se corresponde con las propuestas B y C, muestra un detalle de la sección transversal de las bóvedas en el que se confirma la disposición de vigas entre éstas y los muros. A pesar de ser un elemento intermedio, las vigas quedan asociadas a la cubierta tanto por su material como por su esbeltez, así, son más estrechas que el muro con el fin de marcar el límite entre ambos. Las bóvedas, formadas por tres capas, alcanzan su mínimo espesor estructural en la clave, aunque sobre ellas se dispone un sustrato vegetal, a modo de aislamiento térmico, que incrementa el grosor total de la cubierta. Sobre él se establece un sistema de canales de agua y pasarelas, los primeros destinados al riego de la cubierta, mientras que los segundos facilitan el tránsito por ella, ya que el sustrato vegetal reproduce la ondulación de las bóvedas. Además este documento desvela la función del pequeño volumen que aparece en la cubierta de las perspectivas A, B y C. Se trata de un pabellón abierto que permite maximizar el frescor de la brisa resguardándose del sol y la lluvia en los meses de más calor. 


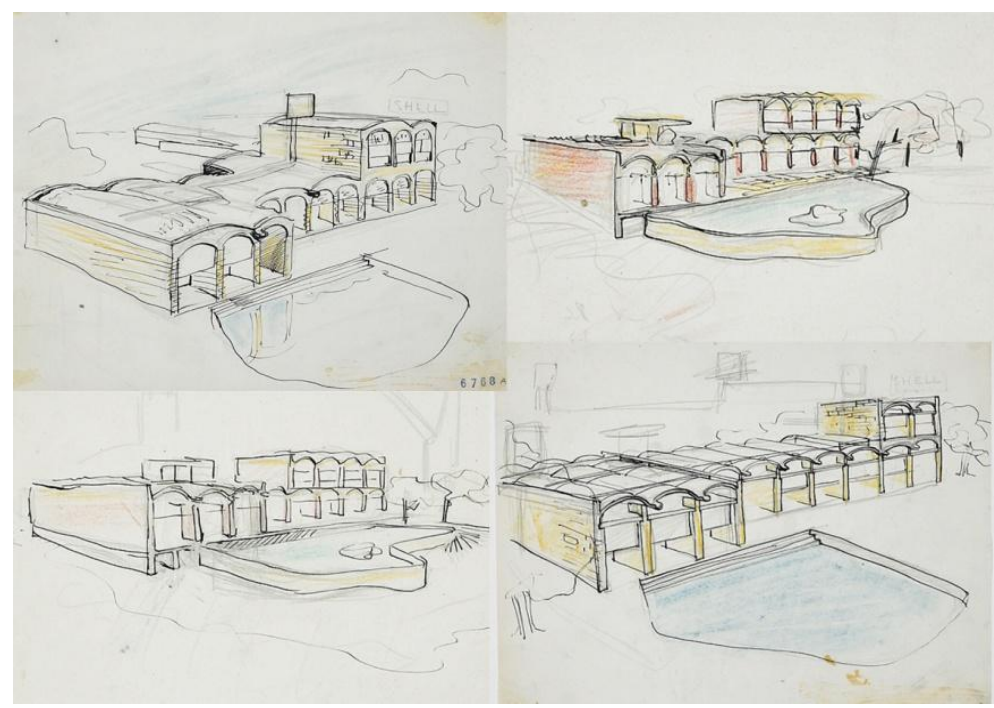

5. Perspectivas exteriores de la Villa Sarabhai desde el Oeste. De arriba a abajo, izquierda a derecha: FLC 6768 A, B, C, D.

En las secciones, FLC 31889 y 31885, dibujadas en junio, se observa que el interés por mostrar con claridad la geometría de las bóvedas en fachada se traslada también al interior. Así pues, todos los espacios situados a caballo entre dos bóvedas tienen su altura limitada a la de la cara inferior de las vigas que las sustentan, impidiendo que la incipiente independencia de la distribución respecto a la estructura altere la percepción de la geometría de la bóveda en el espacio interior. A finales de mes se dibujan nuevos planos de la cubierta, así en el documento FLC 31886, del 20 de junio, se muestra un croquis del ala de Anand en el que además de los sistemas de caminos y canales y de la cabane couverte se muestra un solarium y un trampolín al que se accede por unas escaleras lineales que ya aparecían en las plantas de mayo. El día 21 se delinea el documento FLC 31887, en el que se observa cómo el sistema de croquis se extiende no sólo a toda la cubierta del edificio principal, tanto de planta baja como de planta primera, sino también a la del volumen de servicio, al que se accede mediante una escalera lineal situada en perpendicular a su alzado Nord-Oeste. El diseño de la cubierta como una superficie verde sin barandillas, con caminos y canales, sobre la que se elevan nuevas construcciones remite a una topografía organizada en distintos niveles en lugar de a una cubierta, de modo que desde su superficie todo lo que queda bajo ella se debe considerar producto de una excavación en lugar de una construcción. Si bien es cierto que desde la cubierta de planta baja se divisa el volumen de planta primera, la falta de relaciones visuales entre ellos remite a un muro situado sobre la pradera más que a una parte de la villa.

A diferencia de las terrazas jardín de los años veinte, que se perciben como una habitación sin techo, y del resto de viviendas abovedadas en las que el ajardinamiento es un mero aislante, ya que no ha de ser contemplado por nadie porque la cubierta no es accesible ${ }^{12}$, en la villa Sarabhai el objetivo de Le Corbusier es la búsqueda de la naturalidad:

"Les demi-cylindres des voûtes, une fois l'étanchéité assurée, sont recouverts de terre et le dessus de la maison devient un magnifique jardin de gazons parfaits et de fleurs (...). L'architecte Le Corbusier déclare la guerre en principe, aux jardiniers quels qu'ils soient qui, bien qu'étant envoyés du ciel, donnent un faux visage à la vie en

\footnotetext{
${ }^{12}$ Las cubiertas abovedadas tan sólo tienen un acceso explícito en los estudios de los proyectos de la Saint Baume (1948) y Roq et Rob (1949) cuando por situarse la edificación en un terreno escarpado el acceso se debe realizar por la cubierta. FLC 17773 y 18671 respectivamente.
} 
imposant les plantes précisément exotiques et multipliant exagérément des plantes dénommées «rares», faussant, faussant...sous le couvert de la nature, faussant l'ambiance même" 13

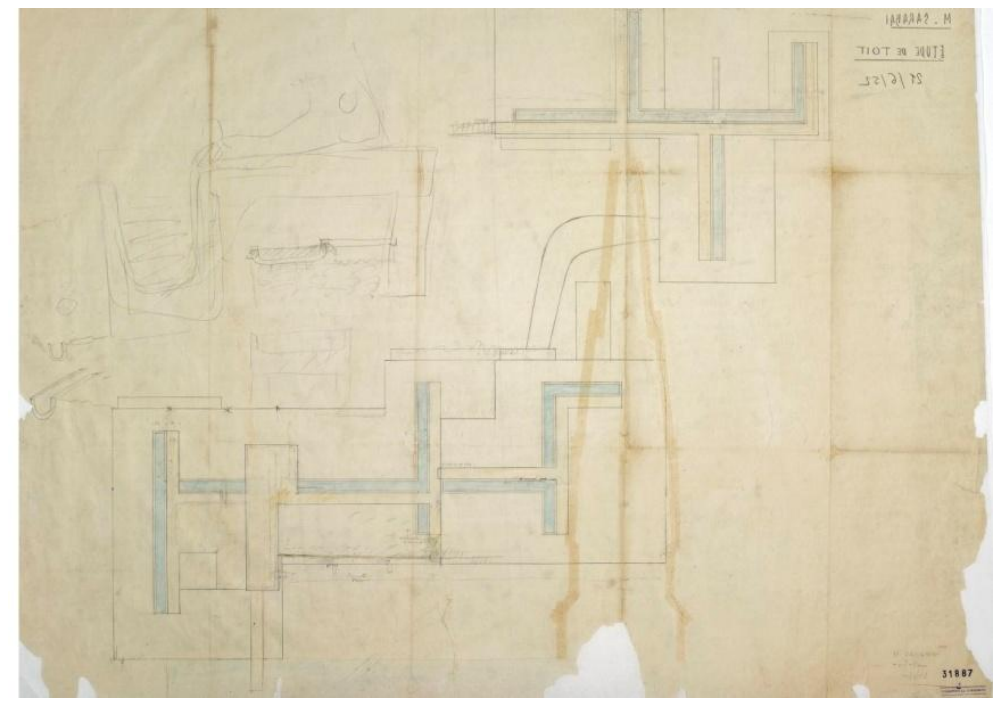

6. Planta de cubiertas de la Villa Sarabhai de junio de 1952. FLC 31887.

\subsection{Un punto discontinuo: la transposición carga soporte}

Entre junio y noviembre se realizan diversos croquis de implantación en los que se estudian los accesos y el contorno de la piscina ${ }^{14}$. En el caso de la piscina, su contorno se va ensanchando y complicando a medida que avanzan las propuestas, alcanzando su punto crítico en el documento FLC 31903, en el que la piscina queda unida a las dos alas del edificio principal haciéndose necesario generar un puente para acceder al otro lado del jardín. En el siguiente documento, FLC 31902, la superficie de la piscina se reduce drásticamente y se aleja del edificio adquiriendo una forma ameboidea, de modo que en lugar de ser un elemento de transición entre la ortogonalidad del edificio y la organicidad del jardín, pasa a formar parte de éste último.

En noviembre se prepara una segunda entrega bajo el nombre de project d'exécution ${ }^{15}$ con motivo del cuarto viaje de Le Corbusier a India. En lo que se refiere a la planta de cubiertas y a la planta baja, las diferencias con la propuesta de junio no son significativas, sin embargo, en el documento FLC 6680 se dibuja por primera vez la planta primera. En ella se refuerza la oposición unidad funcional-unidad espacial de la planta baja, ya que las habitaciones de Mrs Sarabhai y de su hijo menor no se limitan a ocupar cada una su crujía, como en la propuesta de marzo, sino que se maclan en una tercera crujía central, al tiempo que el baño de la Sra Sarabhai se libera de los muros de su nave para ocupar parte de la veranda de la nave contigua. En el diseño de la cubierta se sustituye el trampolín por un tobogán que se desliza desde la cubierta de la cabane couverte hasta la piscina vinculando, mediante el juego, el jardín real con el artificial.

En los alzados principales, dibujados en los documentos FLC 6687 y 6689, se produce una transposición de los conceptos ligero-pesado asociado a los elementos de carga-soporte debido a dos factores. En primer lugar, a la

\footnotetext{
${ }^{13}$ Boesiger, Willy: Le Corbusier et son atelier rue de Sèvres 35. CEuvre complète 1952-1957. 10ª ed. Basel-Boston-Berlin: Birkhäuser Publishers, 1999. p. 114.

${ }^{14}$ Documentos FLC 31906, 31905, 31903, 31902.

${ }^{15}$ Documento FLC P3-5-497 del 11 de noviembre de 1952. Planos enviados: FLC 6691, 6679, 6683, 6693, 6694, 6695A, 6696, 6697, 6698, 6699, 6702, 6703.
} 
desvirtuación del concepto de la bóveda como cáscara, debido al aumento del grosor del canto por la contención de la tierra vegetal de acabado. En segundo lugar, debido al aumento de altura del perfil de los muros, que supera el arranque de las bóvedas otorgando mayor esbeltez al primer elemento y generando ambigüedad en la percepción de la transmisión de cargas.

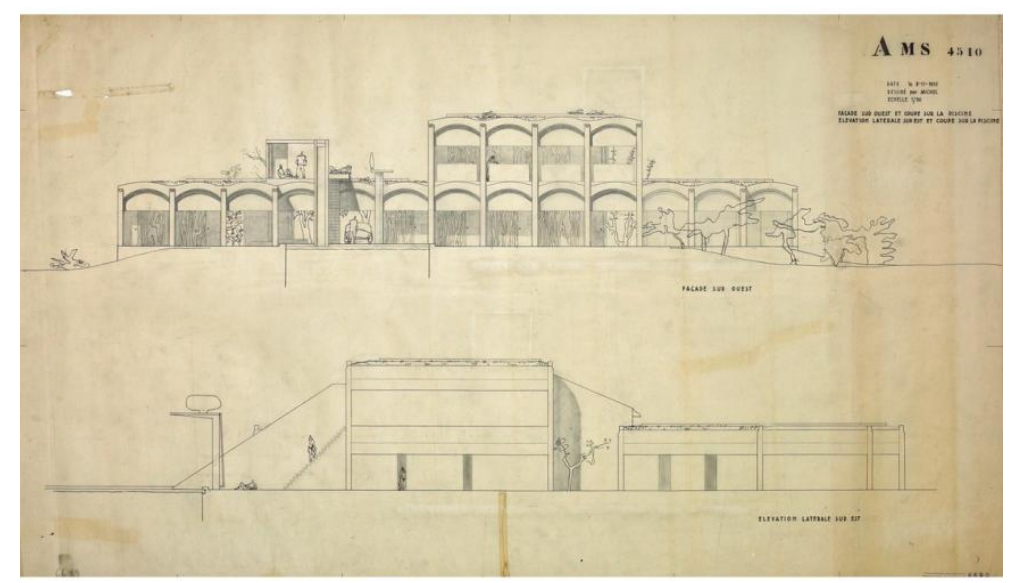

7. Alzados Sud-Oeste y Sud Este de la Villa Sarabhai correspondientes al proyecto de noviembre de 1952. FLC 6687.

\subsection{La oposición forma espacio}

Entre los documentos no fechados del proyecto, se conservan dos perspectivas parciales de la fachada, FLC 6731 y FLC 6769, que indican un estadio intermedio entre los alzados de noviembre de 1952 y los del proyecto definitivo de febrero de 1953. En ellos, la ondulación del extradós de las bóvedas se oculta tras un revestimiento plano de remate horizontal, al tiempo que se maciza su tímpano. Sin embargo, tanto el intradós de las bóvedas como las vigas que las sustentan sobresalen de dicho plano, quedando en vuelo a modo de marquesina. En estos dibujos se observa cómo Le Corbusier intenta modificar el perfil del edificio sin renunciar a la bóveda como elemento compositivo interior-exterior generando una fuerte ambigüedad de sistemas en la fachada.

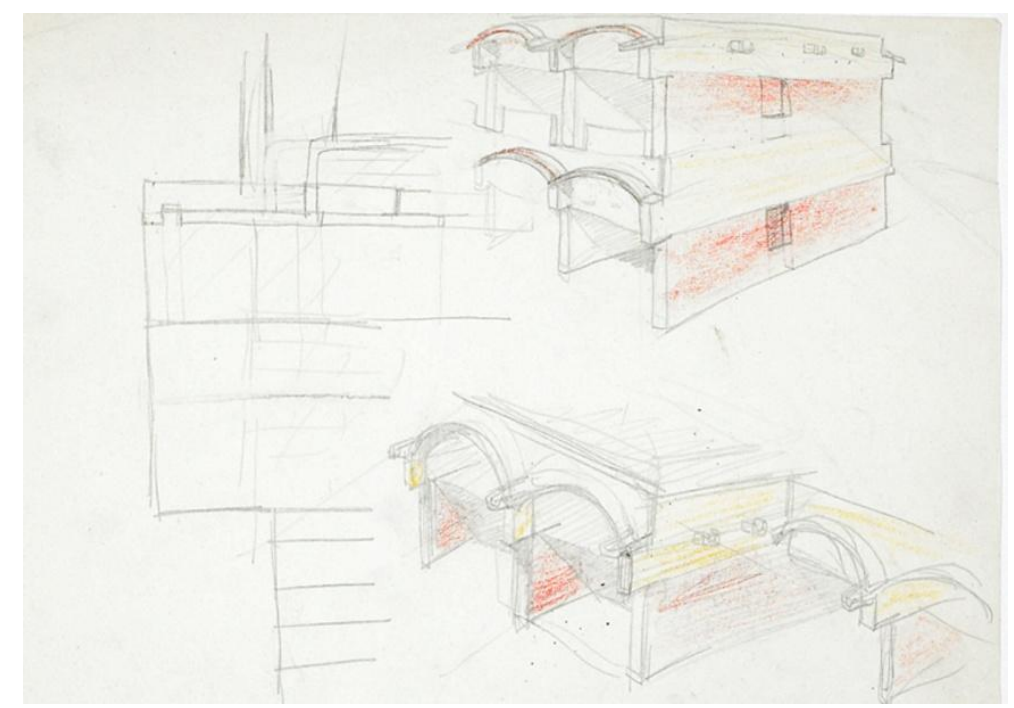

8. Estudio de las fachadas de la Villa Sarabhai realizados entre noviembre de 1952 y febrero de 1953. FLC 6769. 
En febrero de 1953 se prepara un conjunto de planos ${ }^{16}$, entre los que se encuentran planos de ejecución y detalles constructivos que debían ser enviados a la India a final de mes. En el plano de cubierta, FLC 6697, se observa que las pasarelas que acompañaban a los canales de agua desaparecen definitivamente, de modo que toda la cubierta se vuelve una pradera transitable. El documento FLC 6703 muestra como la búsqueda de una estructura de cubierta ligera se lleva hasta sus máximas consecuencias. El espesor de las bóvedas en la clave se reduce a $7 \mathrm{~cm}$, ya que se construyen tan sólo con dos hiladas de ladrillo, de 2 y $5 \mathrm{~cm}$ respectivamente, y sobre ellas se dispone directamente una chapa y una lámina impermeable que quedan protegidas por el sustrato vegetal. El arriostramiento del conjunto se consigue mediante la disposición de tirantes de acero anclados a las vigas de hormigón en las dos bóvedas extremas de cada planta. En las secciones dibujadas en el documento FLC 6696A se observa cómo, mientras en la fachada de acceso la villa surge directamente del terreno, en la fachada del jardín se interpone una losa entre el terreno y la edificación que en algunas zonas queda en vuelo. Sin embargo, de nuevo, los cambios más significativos respecto a la propuesta anterior se encuentran en los alzados, FLC 6693 y 6695. El perfil curvo de las bóvedas de las naves queda oculto en fachada por una ancha franja de hormigón que además limita la altura de los muros tanto en las fachadas principales como en los testeros, restándoles el protagonismo que habían ganado en el proyecto de noviembre. Así, desde el exterior el edificio se percibe como un prisma ortogonal horadado según un patrón modular, mientras que desde el interior el edificio se percibe como una suma de espacios abovedados, de modo que lo recto se opone a lo curvo y la generación de tipo sustractiva a la aditiva.

\subsection{La villa construida. Una máquina de desorientar.}

En la villa construida, cuando se traspasa el umbral de la nave de acceso, situada entre sendas alas, la direccionalidad de la bóveda y la longitud del muro que sustenta el tobogán, invitan a continuar caminando hacia el jardín, resaltado por el marco de penumbra. El espacio, alto y profundo, se percibe con claridad como una unidad de forma simple y límites precisos. Sin embargo, a medida que se avanza, los muros que flanquean el acceso quedan interrumpidos, multiplicándose las visuales. La riqueza espacial de la casa se revela de forma progresiva. Primero se interrumpe el muro de la izquierda, abriéndose una diagonal desde la cual se divisa el acceso al ala principal, aunque lo ajustado de la abertura invita a continuar en la dirección de la bóveda en busca de un camino más amplio. Más adelante se percibe otra interrupción del muro, esta vez a la derecha, abriéndose una nueva diagonal que anuncia el acceso al ala del primogénito. Antes de llegar a ella se localiza el acceso del ala principal, que exige un giro de $90^{\circ}$ consecuencia del cual la percepción del espacio cambia radicalmente. Éste, limitado ahora por la altura de las vigas, se percibe bajo y de límites imprecisos, aunque sigue manteniendo su profundidad.

\footnotetext{
${ }^{16}$ El 27 de febrero de 1953, Le Corbusier envía una carta a Gautam Sarabhai con la lista de planos de la villa Sarabhai que ha enviado a India FLC P3-5-183.
} 


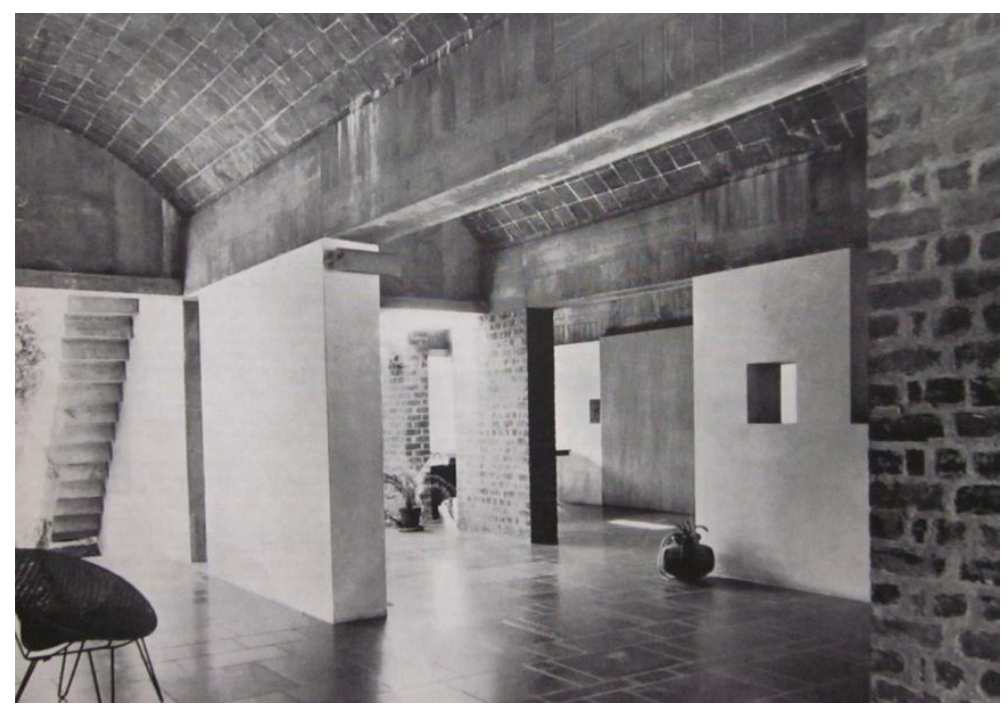

9. Nave de acceso a la Villa Sarabhai dentro del espacio de articulación entre las dos alas del edificio.

Las alineaciones de segmentos de muros con una estudiada alternancia de posiciones, provoca un efecto de laminación del espacio. En palabras del propio Le Corbusier:

"La composition consiste à ouvrir des trous dans ces murs, tout parallèles, en jouant des pleins et des vides. Mais en jouant intensément le jeu architectural" 17

Doshi ${ }^{18}$, uno de los arquitectos que asistieron a Le Corbusier en el proyecto, añade que los muros dan la sensación de ser deslizables gracias a la libertad que les otorgan las vigas de canto. Además explica que la oposición entre la unidireccionalidad espacial de las bóvedas y los movimientos laterales a los que incitan los muros, provoca que la casa se perciba de forma totalmente distinta, no sólo en función de la posición del espectador, sino también, en función de si las puertas de las verandas están abiertas o cerradas. Así, no se identifica un itinerario a seguir y tampoco una jerarquía en la distribución, el espacio fluye en todas direcciones. De este modo, el espacio es igual y diferente a la vez, provocando la desorientación del espectador.

El modo de disponer los materiales en la villa contribuye a la confusión entre interior y exterior. Le Corbusier comenta a propósito de los materiales de la villa:

"Une autre recherche fut poursuivie: reprendre contact avec les matériaux dignes et fondamentaux de l'architecture: la brique amie de l'homme, le béton brut ami aussi, les enduits blancs amis de l'homme, la présence de couleurs intenses provocatrices de joie, etc... "19

Le Corbusier sigue empleando los materiales de acuerdo a los principios establecidos en las Maisons Jacquin y Loucheur en 1929. Cada material, bien concreto, como el ladrillo o el hormigón, bien abstracto, como los enlucidos, se emplea para formar todas las caras de un mismo elemento constructivo. De este modo se consigue que cada uno de ellos se perciba como un volumen independiente, especialmente los muros. No obstante, cuando el muro es enlucido, alguna de sus caras se pinta de un color diferente o se le superpone un mural permitiendo la desintegración volumétrica del elemento de manera puntual. Una primera percepción de la villa permite asociar

\footnotetext{
17 Boesiger, Willy: Euvre complète 1952-1957. Op.cit. p. 114.

${ }^{18}$ Doshi, Balkrishna.V: "The Unfolding of an Achitect". En Global Architecture. "Le Corbusier. Sarabhai house \& Shodhan house". №32. Tokio: A.D.A. EDITA, 1974.

19 Boesiger, Willy: Euvre complète 1952-1957. Op.cit. p. 114.
} 
el material concreto a los segmentos exteriores y el abstracto a los interiores. Sin embargo, cuando el espectador parece haberse orientado, un segundo nivel de percepción revela que en las verandas y en las naves de articulación se emplean tanto enlucidos como materiales vistos, disolviéndose la identificación de un tipo de material con un tipo de espacio, bien interior o bien exterior.

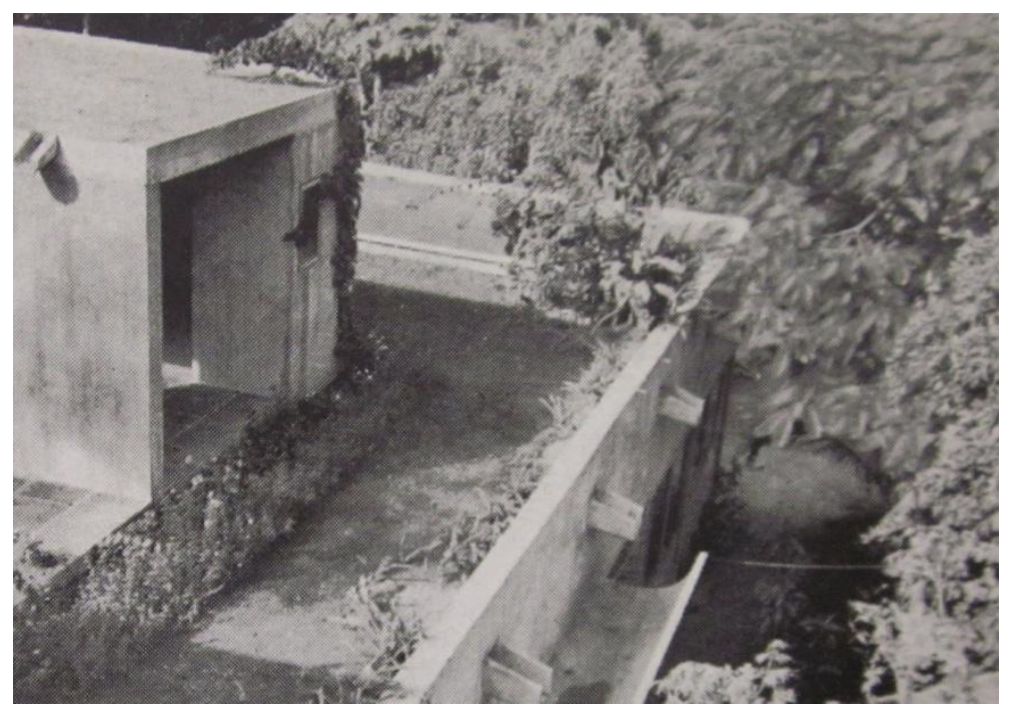

10. Pabellón sobre la cubierta ajardinada de la Villa Sarabhai.

\section{La ambigüedad como herramienta de proyecto}

En el proceso evolutivo de la villa Sarabhai, se observa cómo Le Corbusier intenta despegar el edificio ligeramente del terreno. Primero, sustituyendo el montículo inicial, que impedía las inundaciones, por una elevación de la losa de planta baja sobre los muros; y finalmente, tras recuperar de nuevo el montículo, volando la losa de planta baja respecto a éste en algunas zonas. Le Corbusier había empleado esta estrategia en otras obras consideradas referentes de la architecture femelle como la Villa Henfel (1934), generando ambigüedad entre el peso de los muros, en este último caso de piedra, y la débil relación del edificio con el terreno.

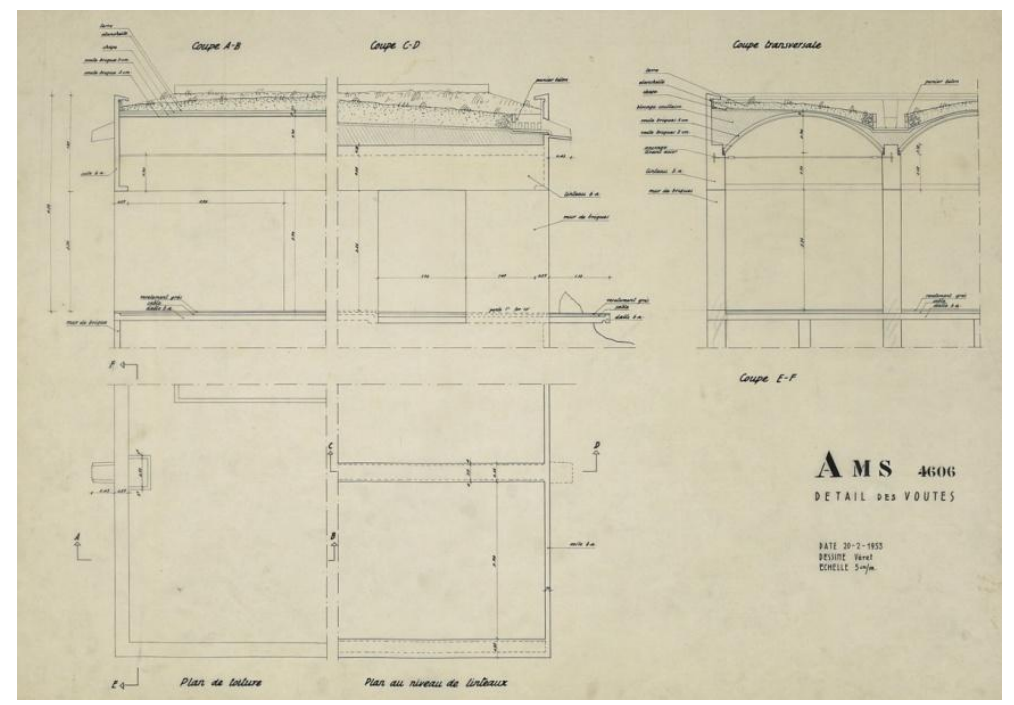

11. Detalle del encuentro del edificio con el terreno de la Villa Sarabhai. FLC 6703

Así pues, no se aprecia la intención de que la villa absorba el emplazamiento a través de su implantación y tampoco su forma contribuye a ello. Como se observa en la evolución formal de la piscina, Le Corbusier emplea 
las envolventes orgánicas para asociar un elemento artificial a un ambiente natural. Sin embargo, la ortogonalidad del edificio, contrasta con las formas orgánicas que lo rodean, y su integración no difiere de la de cualquier villa de Le Corbusier situada en un jardín con arbolado. Si bien es cierto que la mayor parte de la villa se desarrolla en planta baja, los dormitorios de Mrs Sarabhai y su hijo, situados en planta primera, tienen la suficiente entidad como para evitar que la villa pase desapercibida en su entorno. La cubierta jardín no se divisa desde el plano del suelo de modo que no puede considerarse un elemento integrador y tampoco se construye ningún montículo próximo a los testeros, como ocurre en la Villa Henfel (1934), que la oculte parcialmente.

Como apuntaba Serenyi, desde el exterior, la villa tampoco cumple los requisitos del supuesto tipo, ya que, aunque durante la mayor parte del proceso exhibe la ondulación de su cubierta al exterior, en la fase final ésta es ocultada. De este modo se consigue una fuerte sensación de sorpresa cuando se cruza el umbral, ya que ningún rasgo de la envolvente del edificio hace presagiar su interior abovedado. La ambigüedad entre sistema arquitrabado y sistema abovedado para generar desconcierto no es una estrategia surgida por primera vez en este proyecto, Le Corbusier la había empleado en su primer proyecto de villa abovedada, la Villa au bord de la Mer (1916). Cabe resaltar además, que la adscripción del sistema abovedado a un tipo concreto no es tan evidente ya que uno de los ejemplos de architecture mâle más celebrados, la Villa Shodhan, comienza su proceso evolutivo con una cubierta abovedada.

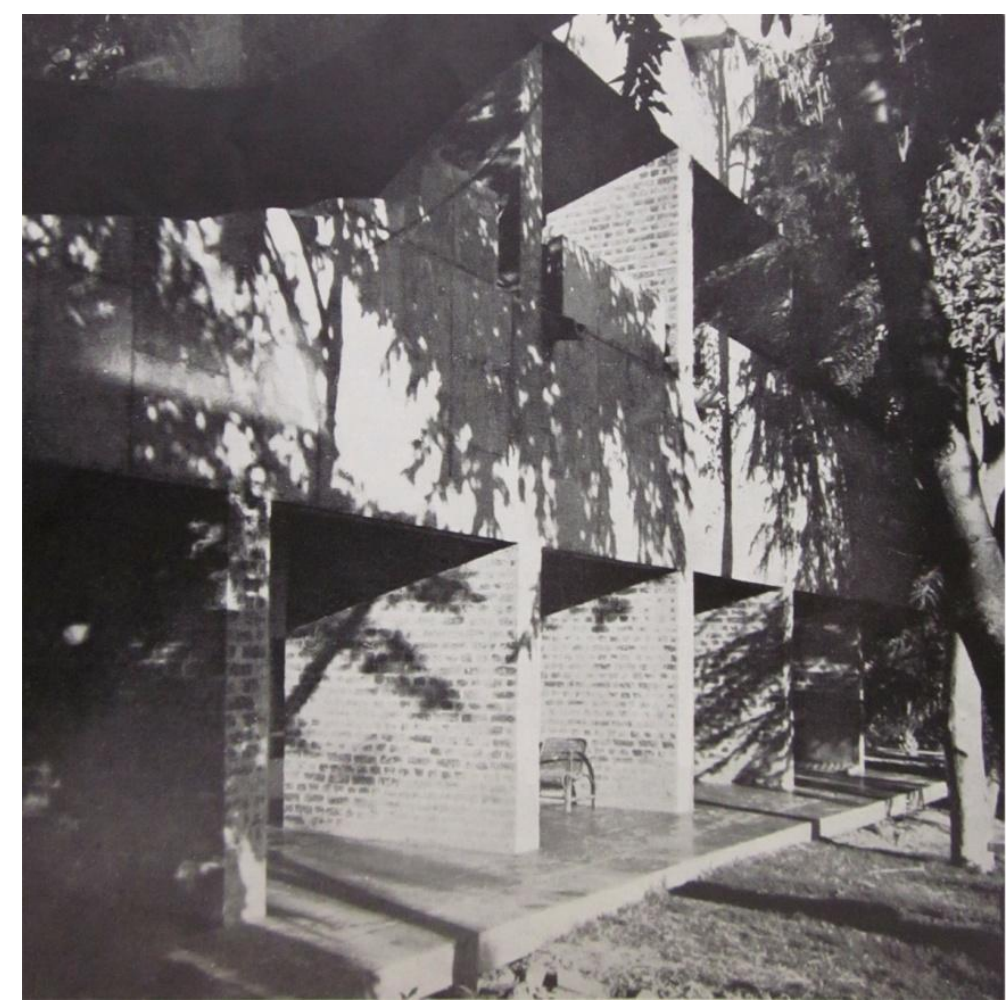

12. Fachada Sud-Oeste de la Villa Sarabhai. 


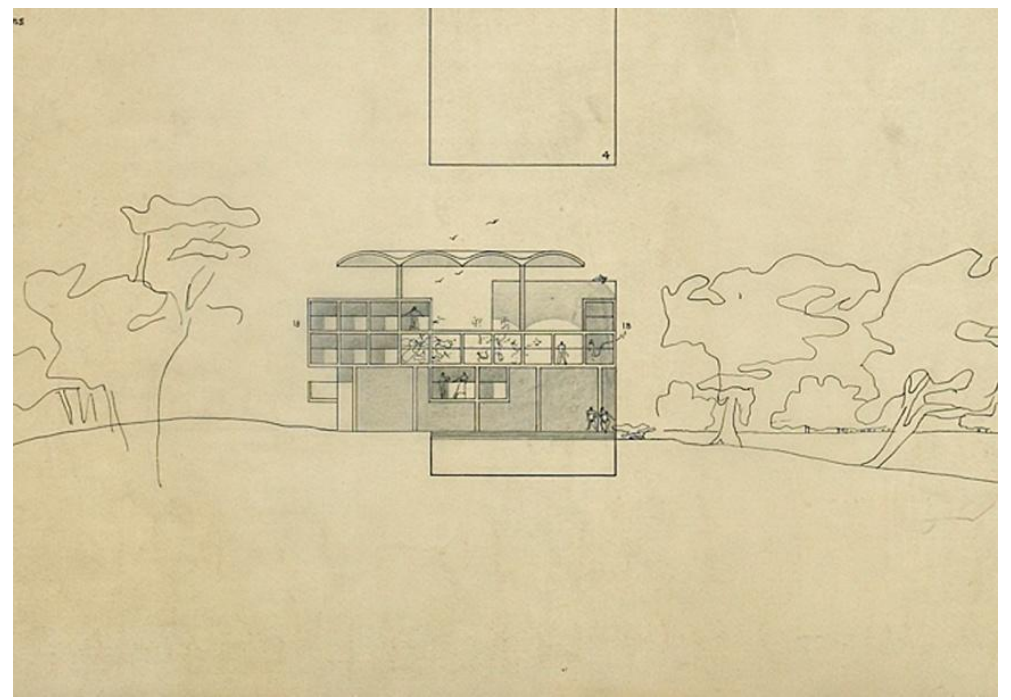

13. Fachada Sud-Oeste de la Villa Shodhan del proyecto de octubre de 1951. FLC 6444A

La asociación del espacio abovedado con una gruta más que con la forma en sí, parece tener que ver con la idea de cubierta pesada y espacios bajos de sombras profundas, ya que el sistema abovedado empleado por Le Corbusier es de tipo modular y por tanto difícil de encontrar como tal en estado natural. Sin embargo, desde las primeras etapas del proyecto, Le Corbusier se esfuerza en reducir al máximo el espesor de la bóveda, teniendo en cuenta la capacidad técnica del país, y si ésta adquiere un canto apreciable es debido a la necesidad de contener el sustrato vegetal que la aísla térmicamente y no atendiendo a una voluntad formal. La asociación del espacio abovedado con un espacio bajo está relacionada con la ausencia de dobles y triples alturas generadas en otros espacios domésticos considerados masculinos, como la Villa Shodhan. La bóveda genera una sensación de compresión-expansión espacial similar a la que generan las dobles alturas, salvo que las primeras lo hacen de forma progresiva y de manera comedida, mientras las segundas lo hacen de forma abrupta. En la primera entrega de la Villa Sarabhai además del espacio abovedado, existe una doble altura asociada al despacho de la Sra Sarabhai, que desaparece en las siguientes propuestas. Sin embargo, en otros proyectos abovedados, como la Cité permanente d'habitation en la Sainte-Baume (1948) o las casas Roq et Rob (1949), si que emplea dobles alturas.

El espacio de la Villa Sarabhai, tampoco parece encajar dentro de referencias primitivas, rupestres o folklóricas. Así cuando Le Corbusier se refiere a las bóvedas de la villa en la Euvre Complète no destaca su rusticidad o pesadez sino virtudes clásicas.

\section{"La beauté des voûtes cylindrées catalanes réclamait le calme",20}

La configuración inicial de la villa parece partir de un sistema basado en la confluencia unidad espacial-unidad funcional asociado tradicionalmente a los sistemas abovedados. Sin embargo, dicha asociación no era un imperativo para Le Corbusier, ya que ya había combinado la planta libre con el sistema abovedado soportado por pilares en proyectos como la Réorganization agraire, ferme et village radieux (1938). Así pues, la limitación inicial de estancias a crujías es resultado de la influencia del proyecto de viviendas adosadas en la Sainte-Baume (1948) o de las investigaciones sobre las Unités d’habitation iniciadas en 1944, en las que las viviendas estaban formadas tan sólo por una o dos crujías debido a la existencia de medianeras.

\footnotetext{
${ }^{20}$ Boesiger, Willy: Euvre complète 1952-1957. Op.cit. p. 114.
} 


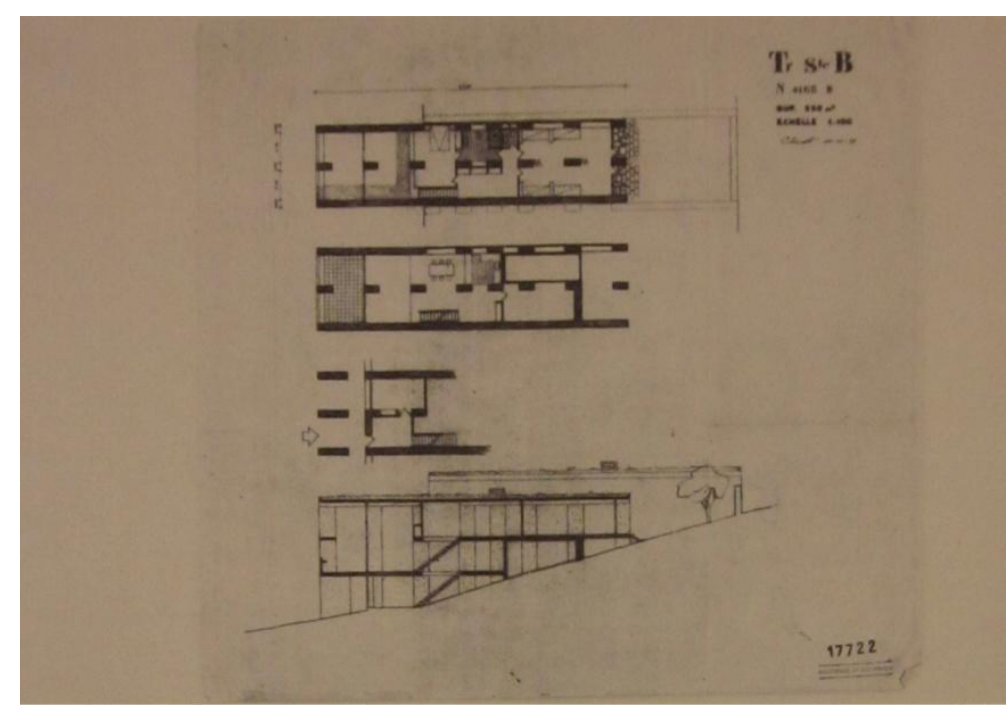

14. Plantas y sección de una de las casas familiares del proyecto de la Basilique en La Saint-Baume de noviembre de 1949. FLC 17722

Cuando Le Corbusier asume que dicha constricción puede ser eliminada debido a la inexistencia de medianeras, comienza a flexibilizar la distribución hasta conseguir una planta tan libre como las de sus proyectos de los años 20, pero en lugar de empleando pilares, mediante el empleo de muros. La elección del sistema de soporte no está vinculada a la tecnología o a la cualificación de la mano de obra del país; ya que la Villa Shodhan, contemporánea y situada en la misma ciudad, sí se construye mediante un entramado de pilares y vigas; ni siquiera a una tradición constructiva, ya que igualmente resulta imprescindible emplear vigas para la distribución de la carga. Así, la elección de un sistema mural atiende a dos razones: una ambiental, facilita el flujo de las brisas a través de la casa evitando su recalentamiento; y otra espacial, laminar horizontalmente el espacio consiguiendo, con una única altura, la misma riqueza espacial de otras de sus obras en las que se combinan espacios de distintas alturas.

En definitiva, la arquitectura de Le Corbusier se resiste a clasificaciones, y la Villa Sarabhai no constituye una excepción, de modo que no se puede considerar un paradigma de la architecture femelle sino del empleo de la ambigüedad como estrategia proyectual. Si se analiza en conjunto el proceso de ideación de la villa, se observa que se trata de un proceso continuo de adición de ambigüedades con el fin de conseguir el mismo efecto anunciado por Le Corbusier en relación a la Villa Savoye:

"Les visiteurs, jusqu'ici, se tournent et se retournent à l'intérieur, se demandant comment tout cela se passe, comprenant difficilement les raisons de ce qu'ils voient et ressentent; (...)Et ...ils ne s'ennuient pas, je crois!” 21

El visitante no es capaz de distinguir si está ante un sistema arquitrabado o abovedado, si está en una casa o en un complejo formado por dos, si está arriba o está abajo, si está dentro o si está fuera. Este proceso alcanza su punto álgido en el primer piso de la villa, cuando Le Corbusier cubre uno de los muros con una fotografía en la que se muestra una de sus esculturas junto a una de sus pinturas apoyada sobre el muro medianero de piedra de su estudio. Así la realidad es sustituida por la representación de otra realidad, resultando difícil la distinción entre ambas.

\footnotetext{
${ }^{21}$ Le Corbusier: Précisions sur un état présent de l'architecture et de l'urbanisme. $6^{\mathrm{a}}$ ed. Paris: Les Éditions G.Crès et $C^{\mathrm{i}}$. p. 136.
} 


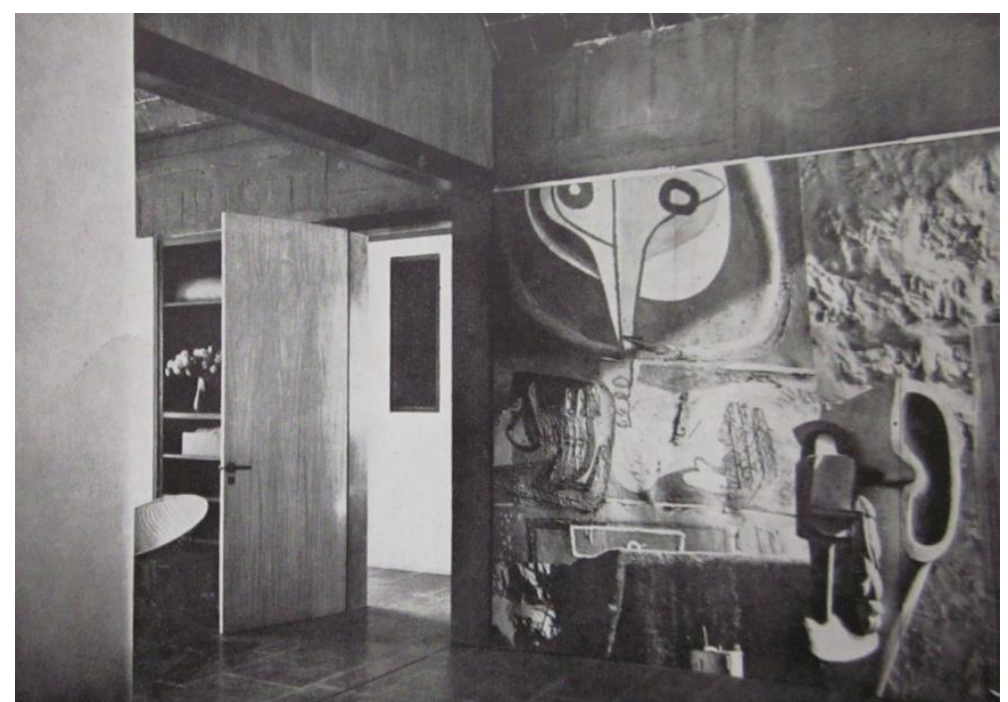

15. Interior de la planta primera de la Villa Sarabhai mostrando un fotomural con dos obras de Le Corbusier dispuesto sobre uno de los muros.

\section{Agradecimientos}

Los autores agradecen a Michel Richard, director de la Fondation Le Corbusier, haber facilitado el acceso al archivo de la Fondation para el desarrollo de esta investigación y la inestimable orientación de Arnau Dercelles, responsable del Centro de Documentación e Investigaciones de la Fondation, en la consulta de los documentos.

\section{Procedencia de las imágenes}

$1,2,3,4,5,6,7,8,11,13,14$. Fondation Le Corbusier.

9, 10, 12,15. ( ) J. Paul Getty Trust. Fotografías de Lucien Hervé. The Getty Research Institute, Los Ángeles (2002.R.41).

\section{Bibliografía/referencias}

Boesiger, Willy: Le Corbusier. Euvre complète 1946-1952. $8^{a}$ ed. Zurich: Les Editions d’Architecture, 1985.

Boesiger, Willy: Le Corbusier et son atelier rue de Sèvres 35. CEuvre complète 1952-1957. 10 a ed. BaselBoston-Berlin: Birkhäuser Publishers, 1999.

Curtis, William: Le Corbusier. Ideas and Forms. London: Phaidon Press Limited, 2003. pp. 210-212.

Doshi, Balkrishna: "Legacies of Le Corbusier and Louis I. Kahn in Ahmedabad". En Architecture and Urbanism. Mayo 2001, No 368.

Doshi, Balkrishna.V: "The Unfolding of an Achitect". En Global Architecture. "Le Corbusier. Sarabhai house \& Shodhan house". N³2. Tokio: A.D.A. EDITA, 1974.

Jencks, Charles: Le Corbusier and the Continual Revolution in Acrchitecture. New York: The Monacelly Press, Inc. and Charles Jencks, 2000.

Le Corbusier: Précisions sur un état présent de l'architecture et de l'urbanisme. $6^{\mathrm{a}}$ ed. Paris: Les Éditions G.Crès et Cie.

Serenyi, Peter: "Le Corbusier`s Changing Attitude Toward Form". En Journal of the Society of Architectural Historians. Marzo 1965, vol XXIV, №2. 
Serenyi, Peter: "Timeless but of its Time: Le Corbusier`s Architecture in India". En Brooks, H.Allen: Le Corbusier. New Jersey: Princeton University Press, 1987.

Suárez, Maria Candela: "Villa de Mrs Manorama Sarabhai". En Le Corbusier plans. CD10. París: Echelle-1 Fondation Le Corbusier, 2005-2010.

Von Moos, Stanislaus: Le Corbusier. Barcelona: Editorial Lumen, 1977. 